\title{
Erratum zu: Acedia-Menschen. Todsünde Trägheit - Gefährdeter Lebenssinn.
}

\section{Alfred Bellebaum}

Im ursprünglichen Werk wurde der Hinweis zur Zitation verlagsseitig fälschlicherweise als eigenes Kapitel 8.3 gesetzt. Dieser Fehler wurde nun behoben.

Des Weiteren wurden zwei im Originalwerk fehlende Literaturangaben ergänzt:

Kasper, E., Kardinal: Papst Franziskus - Revolution der Zärtlichkeit und der Liebe. Theologische Wurzeln und pastorale Perspektiven, darin V: Barmherzigkeit. Irrungen und Wirrungen des Pontifikates, mit Hinweisen auf acedia/Trägheit, S. $37 \mathrm{ff}$.

Papst Franziskus: Die Freude des Evangeliums. Das Apostolische Schreiben „Evangelii gaudium“..., darin „Nein zur egoistischen Trägheit“, S. 121ff. 